\title{
Spontaneous Peripartum Coronary Artery Dissection Presentation and Outcome
}

\author{
George L. Higgins, III, MD, Jennifer S. Borofsky, MD, Christine B. Irish, MD, \\ Thomas S. Cochran, MD, and Tania D. Strout, PhD, RN, MS
}

Objective: The objective of this study was to determine whether spontaneous peripartum coronary artery dissection (SPCAD) is a cause of acute myocardial infarction in women.

Methods: Patients with SPCAD reported in the recent literature were analyzed to elucidate the clinically relevant characteristics of this condition.

Results: Forty-seven cases of SPCAD are described. Patient characteristics include the following: mean age, $33.5 \pm 5.2$ years; gravity, 2.7 (95\% confidence interval, 1.8-3.5); mean gestational age if prepartum, $32.5 \pm 4.2$ weeks (range, $23-36$ weeks); and mean onset if postpartum, $22.9 \pm 26.1$ days (range, 3-90 days). Only 17 patients (36\%) reported a cardiac risk factor, with the most frequent being smoking. All presented with characteristic ischemic pain; $25 \%$ of patients were hemodynamically unstable; and 81\% of initial electrocardiograms demonstrated ST-elevation myocardial infarctions. The left coronary artery system was involved $81 \%$ of the time. Thirty percent of patients were managed conservatively or with thrombolytic therapy, whereas $34 \%$ received emergent percutaneous cardiac intervention and 36\% required bypass surgery. There were no maternal deaths. Long-term follow-up revealed good cardiac function in the majority of patients, although 3 women required heart transplantation.

Conclusions: SPCAD can occur weeks before or after delivery and should be considered in women presenting during the peripartum period with acute chest pain. (J Am Board Fam Med 2013;26:82-89.)

Keywords: Peripartum Coronary Artery Dissection, Spontaneous Coronary Artery Dissection

Spontaneous peripartum coronary artery dissection (SPCAD) is a rare but devastating complication of term pregnancy in women. The majority of the victims are young, have few if any cardiac risk factors, and can dissect days to weeks before or after delivery. They typically incur large myocardial infarctions and present significant challenges to diagnosis and management.

This article was externally peer reviewed.

Submitted 22 January 2012; revised 12 June 2012; accepted 19 June 2012.

From the Department of Emergency Medicine, Maine Medical Center, Portland (GLH, CBI, TSC, TDS); and the Department of Internal Medicine, University of Vermont, Burlington (JSB).

Funding: none.

Prior presentation: This work was presented at the 2010 American College of Emergency Physicians Research Forum, Las Vegas, Nevada (September 28-29, 2010).

Conflict of interest: none declared.

Corresponding author: George L. Higgins, III, MD, Director of Research, Maine Medical Center, Department of Emergency Medicine, 47 Bramhall Street, Portland, ME 04102 (E-mail: higgig@mmc.org).

\section{Goals of This Investigation}

We recently encountered such a patient and describe her case in detail. In addition, we reviewed the current medical literature relating to this condition and report the general characteristics of this patient population, including presenting signs and symptoms, diagnostic clues, management options, and outcomes.

\section{Case Report}

A 25-year old woman presented to the emergency department (ED) with a complaint of pleuritic chest pain. Five days earlier she underwent an uncomplicated cesarean delivery performed at 40 weeks' gestation after attempted elective induction resulted in fetal distress. Her inpatient hospital course was uneventful. After discharge she experienced several brief episodes of sharp chest pain, which were described as mild and transient and resolved spontaneously. On the day of presentation she was breastfeeding her infant when her chest pain recurred and persisted. Initially mild, it be- 
Figure 1. Prehospital electrocardiogram (ECG) demonstrating atrial fibrillation and acute lateral ST-elevation myocardial infarction with reciprocal changes in the inferior leads.

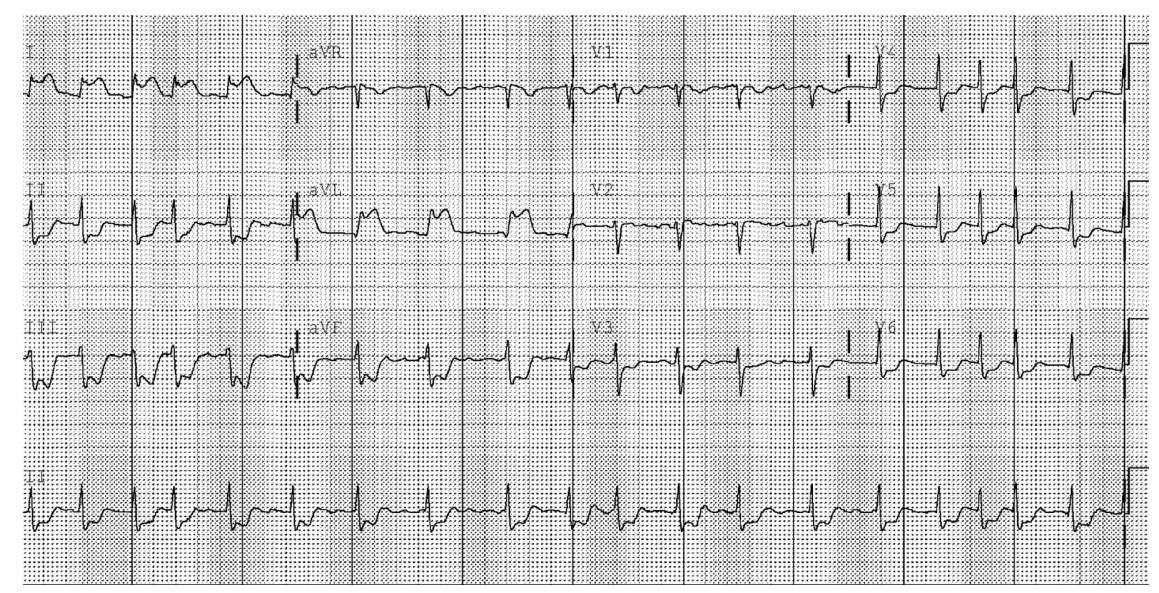

came progressively more severe over the course of several hours, with radiation to her back and left shoulder. In addition, she reported worsening shortness of breath and that deep breaths exacerbated her pain. Her symptoms prompted family members to call their local emergency medical services unit for assistance.

The patient arrived via ambulance, having received morphine and aspirin during transport, and immediately was placed in a critical care bay because of severe respiratory distress. She appeared anxious, pale, and diaphoretic and complained of sharp chest pain that was worse with inspiration. During direct questioning, she denied the presence of fever, chills, lightheadedness, cough, hemoptysis, or calf swelling. She had a history of polycystic ovarian syndrome but no history of deep vein thrombosis or pulmonary embolism. She had no known cardiac risk factors. She was not taking any prescribed medications and denied any current or previous drug abuse, including cocaine. She was a nonsmoker.

In addition to a heart rate of 100 beats per minute and a blood pressure of 126/84 $\mathrm{mm} \mathrm{Hg}$, her initial vital signs were notable for an irregularly irregular tachycardia and an oxygen saturation of $90 \%$ on room air, which was significantly different from the initial prehospital oxygen saturation of $100 \%$, a value obtained approximately 20 minutes earlier at the patient's home. Lung auscultation demonstrated diffuse crackles bilaterally. Heart auscultation revealed an irregular rhythm without murmur or rub. Lower extremity examination was normal without calf tenderness or asymmetry. The remainder of her physical examination was unrevealing.

Review of the prehospital 12-lead electrocardiogram (ECG) demonstrated a sinus rhythm with ST elevation in lead I and L, and ST depression in leads II, III and F. These dynamic changes were confirmed with the initial ECG performed in the ED. In addition, her rhythm now demonstrated atrial fibrillation (Figure 1). Serial ECGs performed during her care in the ED exhibited progression of the ST elevation to include leads V1 and V2, consistent with an evolving anterolateral acute myocardial infarction (AMI), and her atrial fibrillation spontaneously converted to a sinus rhythm (Figure 2).

Given her rapidly deteriorating condition, the patient was intubated quickly for impending hypoxic respiratory failure. Her chest radiograph demonstrated diffuse alveolar opacities bilaterally, consistent with pulmonary edema. A computed tomography scan of the chest was performed immediately to search for thoracic aortic dissection and pulmonary embolus; the interventional team was notified simultaneously of the need for emergent cardiac catheterization. The patient's thoracic computed tomography scan demonstrated only interstitial edema.

The cause of this young and otherwise healthy woman's acute coronary syndrome was suspected to be spontaneous peripartum coronary artery dissection, and she was transferred emergently to the interventional suite for percutaneous cardiac intervention. Catheterization revealed an extensive dissection involving the left main, left anterior de- 
Figure 2. Emergency Department electrocardiogram (ECG) demonstrating return of regular sinus rhythm and evolving antero-spetal ST-elevation myocardial infarction.

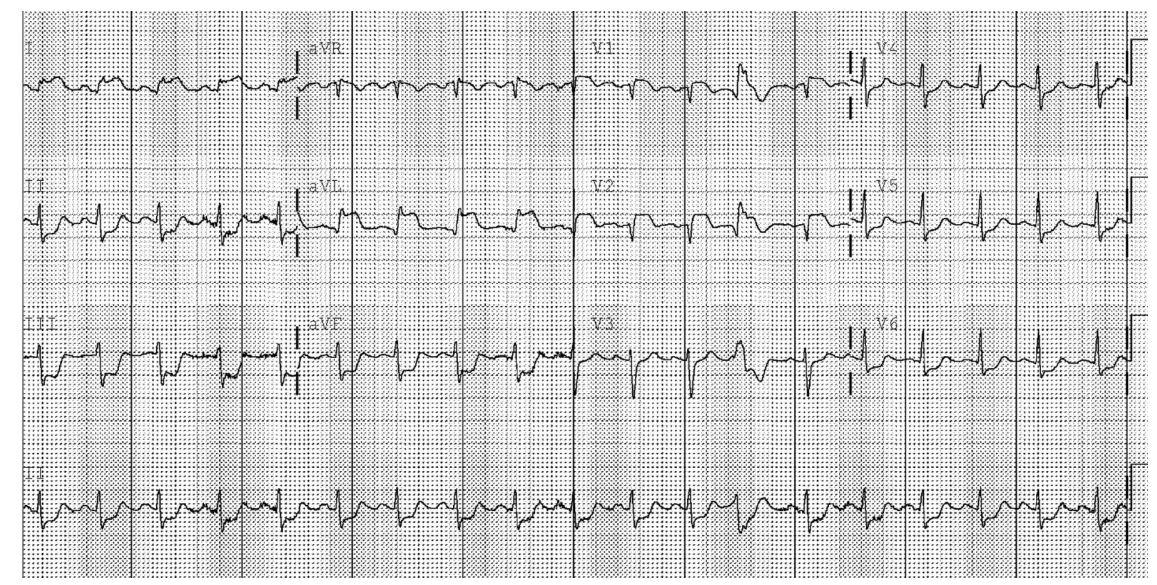

scending, and diagonal coronary arteries (Figure 3). The patient ultimately required surgical revascularization and the placement of a left ventricular assist device. She survived her acute event and subsequently has undergone successful heart transplantation. She now has resumed a relatively normal life with essentially no restrictions.

\section{Methods}

A comprehensive MEDLINE search was conducted, identifying published case reports and case series of pregnancy-related spontaneous coronary

Figure 3. Emergent cardiac catheterization angiogram demonstrating no flow through the left main, left anterior descending and diagonal coronary ateries.

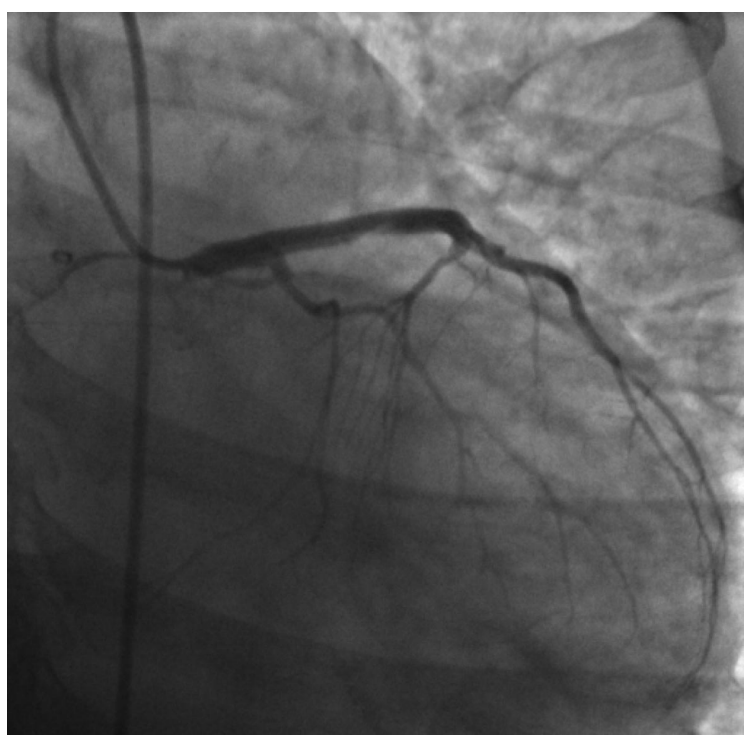

artery dissection. The search was performed using the terms coronary artery dissection or spontaneous coronary artery dissection and either pregnancy or post ${ }^{*}$ partum for articles published between 1996 and the time of the search (July 2009). Only reports published during this time frame were included to minimize variation from current management. All reports of SPCAD occurring during pregnancy or within 90 days of abortion or delivery were included. Using a standardized data extraction tool, the following elements were collected by a single investigator: age, pregnancy and delivery-related complications, timing of SPCAD, cardiovascular risk factors, presenting symptoms, ECG findings, culprit vessels, interventions, and follow-up cardiac function.

Data were entered into a Microsoft Excel (Microsoft Corp., Redmond, WA) spreadsheet program for cleaning and analysis. Descriptive statistics were used to characterize the study population. Summated data are presented as numbers and percentages. Maine Medical Center's institutional review board designated exempted status to this investigation.

\section{Results}

Forty-six published cases of SPCAD were identified. ${ }^{1-44}$ In addition to our sentinel case, these comprise the 47 cases of SPCAD described in this report. Not all data elements were reported in every instance.

Patient demographics, timing of SPCAD, and cardiac risk factors are displayed in Table 1 . The 
Table 1. Patient Age, Cardiac Risk Factors, and Timing of Dissection

\begin{tabular}{|c|c|c|c|}
\hline Case & $\begin{array}{c}\text { Age } \\
\text { (years) }\end{array}$ & Timing of SPCAD & $\begin{array}{c}\text { Cardiac Risk } \\
\text { Factors }\end{array}$ \\
\hline 1 & 38 & 28 days postpartum & None \\
\hline 2 & 26 & 34 weeks gestation & None \\
\hline 3 & 34 & 7 days postpartum & None \\
\hline 4 & 31 & 8 days postpartum & None \\
\hline 5 & 30 & 5 days postpartum & HL \\
\hline 6 & 26 & 90 days postpartum & None \\
\hline 7 & 52 & 10 days postpartum & None \\
\hline 8 & 37 & 21 days postpartum & None \\
\hline 9 & 26 & 14 days postpartum & Smoker \\
\hline 10 & 33 & 10 days postpartum & NR \\
\hline 11 & 34 & 34 weeks gestation & HTN, smoker \\
\hline 12 & 41 & 8 days postpartum & None \\
\hline 13 & 32 & 34 weeks gestation & FH, HTN, smoker \\
\hline 14 & 32 & 63 days postpartum & FH \\
\hline 15 & 35 & 11 days postpartum & Smoker \\
\hline 16 & 34 & 35 days postpartum & None \\
\hline 17 & 34 & 7 days postpartum & None \\
\hline 18 & 34 & 32 weeks gestation & None \\
\hline 19 & 36 & 36 weeks gestation & None \\
\hline 20 & 31 & 30 days postpartum & NR \\
\hline 21 & 29 & 4 days postpartum & None \\
\hline 22 & 38 & 14 days postpartum & None \\
\hline 23 & 34 & 84 days postpartum & None \\
\hline 24 & 31 & 3 days postpartum & None \\
\hline 25 & 37 & 8 days postpartum & $\mathrm{FH}$ \\
\hline 26 & 23 & 60 days postpartum & Smoker \\
\hline 27 & 38 & 34 weeks gestation & FH, HL \\
\hline 28 & 39 & 7 days postpartum & None \\
\hline 29 & 22 & 10 days postpartum & Smoker, HL \\
\hline 30 & 36 & 34 weeks gestation & None \\
\hline 31 & 37 & 60 days postpartum & None \\
\hline 32 & 33 & 26 weeks gestation & Smoker \\
\hline 33 & 33 & 26 weeks gestation & NR \\
\hline 34 & 31 & 8 days postpartum & None \\
\hline 35 & 35 & 14 days postpartum & HTN \\
\hline 36 & 32 & 3 days postpartum & None \\
\hline 37 & 37 & days postpartum & None \\
\hline 38 & 24 & 35 weeks gestation & None \\
\hline 39 & 36 & 28 days postpartum & FH \\
\hline 40 & 34 & 5 days postpartum & Smoker \\
\hline 41 & NR & 36 weeks gestation & None \\
\hline 42 & 40 & 7 days postpartum & None \\
\hline 43 & 32 & 7 days postpartum & HTN \\
\hline 44 & 37 & 4 days postpartum & Smoker \\
\hline 45 & 29 & 23 weeks gestation & None \\
\hline 46 & 34 & 84 days postpartum & $\mathrm{FH}$ \\
\hline 47 & 25 & 5 days postpartum & None \\
\hline
\end{tabular}

FH, family history; HL, hyperlipidemia; HTN, hypertension; NR, not reported; SPCAD, spontaneous peripartum coronary artery dissection. mean age of these women was $33.5 \pm 5.2$ years [95\% confidence interval [CI], 31.9-35). The majority reported having previous uneventful pregnancies (mean gravity, 2.7 [95\% CI, 1.8-3.5]).

The presence or absence of cardiac risk factors was documented in 44 cases. Seventeen patients (39\%) reported at least one cardiovascular risk factor, with the most frequent being smoking history (23\%), family history (16\%), hypertension (9\%), and lipid disorder (7\%). However, only 4 women (9\%) had more than one risk factor, whereas 27 (61\%) reported no known risk factors. No case reported associated illicit substance use such as cocaine.

Thirty-five women (74\%) developed SPCAD during the postpartum period, with a mean interval of $22.9 \pm 26.1$ days (range, 3-90 days) after delivery. Two of these women experienced SPCAD after aborted pregnancies. For those women developing SPCAD during pregnancy, the mean gestational age was $32.5 \pm 4.2$ weeks (range, 23-36 weeks).

Patient presenting symptoms, initial ECG changes, identification of the culprit vessel(s), and therapeutic interventions are displayed in Table 2. All patients presented shortly after experiencing chest pain, which was described uniformly with classic ischemic modifiers suggestive of acute coronary syndrome. Associated symptoms and signs were reported in 44 cases and most frequently included dyspnea (34\% of patients) and diaphoresis (30\% of patients). Seven women (16\%) had experienced previous self-limited chest pain.

Ten women (25\%) were hemodynamically unstable at the time of presentation; this was defined as hypotension, bradycardia, reported cardiogenic shock, or ventricular fibrillation. Six patients (14\%) received advanced cardiac life support interventions and $12(26 \%)$ required emergent intra-aortic balloon pump support.

All women experienced AMI as a result of their SPCAD. Specific initial ECG findings were reported in 42 cases. Of these, 34 (81\%) demonstrated STelevation myocardial infarctions. Cardiac catheterization, intravenous ultrasound, multidetector computerized tomography, or a combination of these modalities was used to identify the culprit vessel(s). The left coronary artery system (left main, left anterior descending, left circumflex, or a combination of these vessels) was involved $81 \%$ of the time (38 cases), whereas the right coronary artery was the 
Table 2. Patient Complaints, Electrocardiogram (ECG) Changes, Culprit Vessel(s), and Treatment

\begin{tabular}{|c|c|c|c|c|}
\hline Case & Presenting Complaint/Status & Type of AMI & Culprit Vessel(s) & Treatment \\
\hline 1 & Chest pain & STEMI & LAD, LCX & IABP, PCI $(\times 2)$ \\
\hline 2 & Chest pain & STEMI & Left main & IABP, CABG \\
\hline 3 & Chest pain & STEMI & LAD & PCI $(\times 2)$ \\
\hline 4 & Chest pain & NSTEMI & RCA & PCI \\
\hline 5 & Chest pain, HDI & STEMI & LAD & Lytics, IABP, PCI, transplant \\
\hline 6 & Chest pain & STEMI & $\mathrm{LAD}$ & Medical \\
\hline 7 & Chest pain & STEMI & Left main, LAD, RCA, LCX & IABP, CABG \\
\hline 8 & Chest pain & STEMI & LCX & Medical \\
\hline 9 & Chest pain, SOB & NSTEMI & LAD & CABG \\
\hline 10 & Chest pain, diaphoresis & STEMI & RCA & PCI \\
\hline 11 & Chest pain, diaphoresis, SOB & STEMI & Left main, LAD, LCX & CABG \\
\hline 12 & Chest pain & STEMI & Distal branches & Medical \\
\hline 13 & Chest pain, diaphoresis, SOB, SLCP & NSTEMI & LAD & Medical \\
\hline 14 & Chest pain & NSTEMI & LAD, LCX & PCI \\
\hline 15 & Chest pain, SLCP & STEMI & $\mathrm{LAD}$ & Medical \\
\hline 16 & Chest pain, SLCP & STEMI & Left main, LAD & Medical \\
\hline 17 & Chest pain & NSTEMI & $\mathrm{LAD}$ & Medical \\
\hline 18 & Chest pain, SOB, HDI & STEMI & RCA & PCI $(\times 2)$ \\
\hline 19 & Chest pain, HDI & STEMI & LAD & IABP, CABG \\
\hline 20 & Chest pain & STEMI & Left main & Lytics, IABP, CABG, transplant \\
\hline 21 & Chest pain, SOB, HDI & STEMI & Left main, LAD, LCX & IABP, CABG \\
\hline 22 & Chest pain, diaphoresis & AMI & Left main, LAD & CABG \\
\hline 23 & Chest pain, diaphoresis, SOB & STEMI & Left main & IABP, CABG \\
\hline 24 & Not reported & AMI & Left main, LAD & PCI \\
\hline 25 & Chest pain, diaphoresis, SOB & STEMI & Left main, LAD & CABG \\
\hline 26 & Chest pain, diaphoresis, SOB, HDI & STEMI & Left main, LAD, LCX & $\mathrm{IABP}, \mathrm{PCI}$ \\
\hline 27 & Chest pain, SOB & STEMI & LAD & Medical \\
\hline 28 & Chest pain, diaphoresis, SOB & NSTEMI & LAD, RCA, LCX & Medical \\
\hline 29 & Chest pain & NSTEMI & $\mathrm{LAD}$ & Medical \\
\hline 30 & Chest pain, diaphoresis, HDI & STEMI & RCA & PCI \\
\hline 31 & Chest pain, SLCP & STEMI & $\mathrm{LAD}$ & Medical, lytics \\
\hline 32 & Chest pain & NSTEMI & Left main & IABP, CABG \\
\hline 33 & Chest pain, SLCP, HDI & STEMI & Left main, LAD, LCX & IABP, CABG \\
\hline 34 & Chest pain & STEMI & $\mathrm{LAD}$ & Medical \\
\hline 35 & Chest pain, diaphoresis, SOB & STEMI & LAD & Lytics, IABP, PCI \\
\hline 36 & Chest pain, SOB & STEMI & Left main & CABG \\
\hline 37 & Not reported & AMI & $\mathrm{LAD}$ & Lytics, PCI \\
\hline 38 & Chest pain & AMI & LAD & Medical \\
\hline 39 & Chest pain, diaphoresis, SOB & STEMI & $\mathrm{LAD}$ & Medical \\
\hline 40 & Chest pain & STEMI & $\mathrm{LAD}$ & PCI \\
\hline 41 & Chest pain, diaphoresis, SOB, HDI & STEMI & RCA & PCI \\
\hline 42 & Chest pain, diaphoresis, HDI & STEMI & LAD & PCI \\
\hline 43 & Chest pain, SOB, HDI & STEMI & Left main & IABP, CABG \\
\hline 44 & Chest pain & AMI & LAD, LCX & PCI, CABG \\
\hline 45 & Chest pain & STEMI & LAD, RCA & PCI \\
\hline 46 & Chest pain, SLCP & STEMI & Left main, LAD & IABP, CABG \\
\hline 47 & Chest pain, HDI, SOB & STEMI & Left main, LAD & IABP, CABG, LVAD, transplant \\
\hline
\end{tabular}

AMI, acute myocardial infarction (ST segment changes not specified); CABG, coronary artery bypass graft; HDI, hemodynamic instability; IABP, intra-aortic balloon pump; LAD, left anterior descending; LVAD, left ventricular assist device; LCX, left circumflex; NSTEMI, non-ST elevation myocardial infarction; PCI, percutaneous intervention; RCA, right coronary artery; SOB, shortness of breath; SLCP, self-limited chest pain; STEMI, ST elevation myocardial infarction. 
culprit vessel in 5 cases (11\%). Both left and right coronary artery systems were involved in 3 cases (6\%); in one instance the dissection was described as involving only "small branches."

It is not surprising that the reported treatment strategies used in this cohort of young women with acute coronary syndrome favored procedural over pharmacological interventions. Seventeen women (36\%) underwent emergent coronary artery bypass grafting, 16 (34\%) received emergent percutaneous intervention, and 14 patients (30\%) were managed with either conservative medical or thrombolytic therapy.

Patient outcome data were reported based on patient condition at discharge or at various follow-up appointments. Numerous outcome measures were described, making it difficult to compare cases or identify trends. However, no cases of maternal death were reported, although fetal demise was directly attributed to intrapartum SPCAD in 3 instances (6\%). Long-term follow-up, when described, revealed good cardiac function in the majority of patients. Three women eventually underwent successful heart transplantation.

\section{Discussion}

Patients younger than age 45 years account for approximately $10 \%$ of AMIs in the United States. The majority of this subpopulation are men with known cardiac risk factors and occult atherosclerotic coronary artery disease. ${ }^{1}$ It is fortunate that peripartum AMI is an uncommon event. A recent US population-based report estimated the incidence of AMI to be 1 in every 16,129 pregnancies, with a mortality rate of approximately $5 \% .{ }^{45} \mathrm{Al}-$ though most of these women are documented to have typical atherosclerotic obstructive coronary artery disease as the cause of their AMI, up to 1 in 4 will prove to have SPCAD. ${ }^{46}$ The initial diagnostic approach to these young, pregnant women with suspected acute coronary syndrome obviously will be the same, with most undergoing emergent diagnostic coronary artery catheterization, which should differentiate atherosclerotic disease from dissection. However, it is prudent to remember that the ideal management of these patients differs, as described below, and it is important to keep SPCAD on the list of differential diagnoses when dealing with this specific subpopulation of patients.

The incidence of spontaneous coronary artery dissection for the general population with AMI is estimated to be less than $1 \% .{ }^{47}$ However, approximately $25 \%$ of pregnant women who experience AMI are found to have SPCAD as the cause, suggesting that hormonal and physiologic factors associated with pregnancy likely play a contributing role. Postulated pathophysiological mechanisms include pregnancy; labor- and delivery-induced increases in cardiac output and arterial sheer forces; alterations in collagen synthesis; increased progesterone and estrogen levels; and alterations in the coagulation and fibrinolysis systems, resulting in a prothrombotic state. ${ }^{4,7,46}$ The end result is a coronary artery hemorrhagic dissection, with or without an intimal tear, that usually begins within $2 \mathrm{~cm}$ of the aortic ostium, extends distally, and compresses the true lumen.

Before the widespread and immediate availability of advanced cardiac services, short-term patient mortality from SPCAD approached $40 \% .^{4}$ It is reassuring that our review of all cases reported during the era of more advanced therapeutic cardiac options failed to identify a single case of maternal mortality. It is possible, however, that publication bias may be contributing to these impressive outcomes.

Our analysis indicates that women with SPCAD can present weeks before delivery (a mean gestational age of 32.5 weeks, with a lower-end range of 23 weeks) or after delivery (a mean of 30 days postpartum, with an upper-end range of 90 days). Therefore, we suggest asking women of childbearing age who present with signs and symptoms suggestive of acute coronary syndrome about their recent obstetric history. In addition, we found that these women are less likely to have predisposing cardiac risk factors and usually present relatively soon after the onset of classic symptoms of ischemic pain. Acute dyspnea and diaphoresis often are experienced as well. One of 4 women will be hemodynamically unstable at the time of arrival at the ED.

The majority of patients with SPCAD will demonstrate electrocardiographic evidence of an STsegment elevation myocardial infarction, most often in a left coronary artery system distribution. This reflects that more than $80 \%$ of these dissections involve the left coronary artery and its major divisions. For the pregnant woman undergoing emergent diagnostic cardiac catheterization, all possible measures should be implemented to protect the fetus from harmful exposure to radiation.

Historically, some women with SPCAD survived with relatively good functional outcomes us- 
ing medical therapy alone. Most received intravenous heparin without anecdotal reports of adverse effects. However, there also is anecdotal and theoretical evidence to suggest that thrombolytics may potentiate the hemorrhagic dissection. ${ }^{48,49}$ In addition, thrombolytics are relatively contraindicated during pregnancy (class $\mathrm{C}$, with no reliable studies reported). ${ }^{7}$ It is important to weigh the potential benefits of thrombolytic therapy with the risks of harm in every specific circumstance. It has been recommended that thrombolytics should be avoided for at least 2 weeks after delivery of the fetus. $^{22}$

The currently preferred management option for SPCAD is percutaneous coronary intervention if the dissection is anatomically amenable to stenting. However, given the nature of these lesions, coronary artery bypass graft surgery is often required. Finally, it should be emphasized that women with prepartum SPCAD should be managed by a multidisciplinary team, including an obstetric consultant. ${ }^{12}$ These women seem to have a high likelihood of surviving their event with near-normal long-term cardiac function.

A potential limitation of this review should be mentioned. There is the possibility of publication bias, with cases demonstrating favorable clinical outcomes being preferentially submitted for consideration. However, reviewing the medical literature (mainly case reports) before our cutoff of 1996 suggests that the maternal and fetal mortality from this condition was not insignificant. Therefore, the impressively favorable outcomes observed in our review (no reported maternal mortality) might well represent the impact of recent advances in the overall care of patients experiencing acute coronary syndromes coupled with the general health of this selected patient population.

\section{Conclusion}

It is important for clinicians to consider SPCAD in women of childbearing age who present with signs and symptoms consistent with an acute coronary syndrome. Obtaining a recent obstetric history will identify the possibility of this condition. SPCAD can mimic other more common pregnancy-related conditions such as pulmonary embolism, resulting in a delay in diagnosis and definitive management.

\section{References}

1. Choudry L, Marsh JD. Myocardial infarction in young patients. Am J Med 1999;107:254-61.

2. Maeder M, Ammann P, Angehrn W, et al. Idiopathic spontaneous coronary artery dissection: incidence, diagnosis and treatment. Int J Cardiol 2005;101:363-9.

3. Roig S, Gomez JA, Fiol M, et al. Spontaneous coronary artery dissection causing acute coronary syndrome: an early diagnosis implies a good prognosis. Am J Emerg Med 2003;21:549-51.

4. Koul AK, Hollander G, Moskovits N, et al. Coronary artery dissection during pregnancy and the postpartum period: two case reports and review of literature. Catheter Cardiovasc Interv 2001;52:88-94.

5. Azzarelli S, Fiscella D, Amico F, et al. Multivessel spontaneous coronary artery dissection in a postpartum woman treated with multiple drug-eluting stents. J Cardiovasc Med (Hagerstown) 2009;10:340-3.

6. Rahman S, Abdul-Waheed M, Helmy T, et al. Spontaneous left main coronary artery dissection complicated by pseudoaneurysm formation in pregnancy: role of CT coronary angiography. J Cardiothorac Surg 2009;4:15.

7. Appleby CE, Barolet A, Ing D, et al. Contemporary management of pregnancy-related coronary artery dissection: a single-centre experience and literature review. Exp Clin Cardiol 2009;14:e8-16.

8. Bilgehan K, Roffi M. Postpartal dissection of all coronary arteries in an in vitro-fertilized postmenopausal woman. Texas Heart Inst J 2009;36:168-70.

9. Van den Branden BJL, Bruggeling WAJ, Corbeij HMA, et al. Spontaneous coronary artery dissection in the postpartum period. Neth Heart J 2008;16:412-4.

10. Patel KP, Sotolongo RP, Myrick TW. Off-pump coronary artery bypass grafting for spontaneous coronary artery dissection in a 26 -year-old patient two weeks post-partum: a case report and review. J Extra Corpor Technol 2008;40:127-9.

11. Iltumur K, Karahan Z, Ozmen S, Danis R, Toprak N. Spontaneous coronary artery dissection during hemodialysis in the post-abortion period. Int J Cardiol 2008;127:e45-7.

12. Sherif HMF, Nguyen HC, Sarter BH, et al. Spontaneous coronary artery dissection in later pregnancy: a multidisciplinary approach to management. Ann Thorac Surg 2008;85:1793-4.

13. Collyer M, Bellenger N, Nachimuthu P, Parasuraman R, Taylor MJ. Postpartum coronary artery dissection. J Obstet Gynaecol 2008;28:451-3.

14. Shahabi S, Smith NA, Chanana C, et al. Pregnancyassociated myocardial infarction: a report of two cases and review of the literature. Upsala J Med Sci 2008;113:325-30.

15. Kalra N, Greenblatt J, Ahmed S. Postpartum spontaneous coronary artery dissection (SCAD) managed conservatively. Int J Cardiol 2008;129:e53-5.

16. Satoda M, Takagi K, Uesugi M, et al. Acute myocardial infarction caused by spontaneous postpartum 
coronary artery dissection. Nat Clin Pract Cardiovasc Med 2007;4:688-92.

17. Kiernan TJ, Rochford M. Postpartum spontaneous coronary artery dissection: an important clinical link with anticardiolipin antibody. Int J Cardiol 2007;114:e75-6.

18. Schiff JH, Gries A, Ehehalt R, et al. A pregnant woman with acute myocardial infarction due to coronary artery dissection: pre-hospital and in-hospital management. Resuscitation 2007;73:467-74.

19. Aliyary S, Mariani MA, Verhorst PMJ, et al. Staged therapeutic approach in spontaneous coronary artery dissection. Ann Thorac Surg 2007;83:1879-81.

20. Paez M, Buisan F, Herrero E. Spontaneous dissection of the left coronary artery trunk during the postpartum period treated with revascularization surgery, ventricular assistance, and a successful heart transplant. Acta Anaesthesiol Scand 2007;51:960-1.

21. Goland S, Schwarz ER, Siegel RJ, et al. Pregnancyassociated spontaneous coronary artery dissection. Am J Obstet Gynecol 2007;197:e11-3.

22. Frey BW, Grant RJ. Pregnancy-associated coronary artery dissection: a case report. J Emerg Med 2006; 30:307-10.

23. Gasparovic H, Ugljen R, Coric V, et al. Surgical treatment of postpartal spontaneous left main coronary artery dissection. Thorac Cardiov Surg 2006;54:70-1.

24. Chabrot P, Motreff P, Boyer L. Postpartum spontaneous coronary artery dissection: a case of pseudoaneurysm evolution detected on MDCT. AJR Am J Roentgenol 2006;187:W660.

25. Rogers IS, Rinaldi MJ, Humphrey CB, et al. Postpartum dissection of the left main coronary artery. Clin Cardiol 2006;29:175-8.

26. Luceri S, Paolillo V, De Benedictis M, et al. Spontaneous dissection of the left coronary tree after an interruption of pregnancy treated with extensive stenting. J Invasive Cardiol 2006;18:117-20.

27. Phillips LM, Makaryus AN, Beldner S, Spatz A, Smith-Levitin M, Marchant D. Coronary artery dissection during pregnancy treated with medical therapy. Cardiol Rev 2006;14:155-7.

28. Schroder C, Stoler RC, Branning, Choi JW. Postpartum multivessel spontaneous coronary artery dissection confirmed by coronary CT angiography. Proc (Bayl Univ Med Cent) 2006;19:338-41.

29. Nallamothu BK, Saint M, Saint S, Mukherjee D. Double jeopardy. N Engl J Med 2005;353:75-80.

30. Terrovitis JV, Kanakakis J, Nanas JN. Spontaneous coronary artery dissection as a cause of acute myocardial infarction in the postpartum period. Cardiol Rev 2005;13:211-3.

31. Shah P, Dzavik V, Cusimano RJ, et al. Spontaneous coronary artery dissection of the left main coronary artery. Can J Cardiol 2004;20:815-8.

32. Tang ATM, Cusimano RJ. Spontaneous coronary artery dissection complicating midterm pregnancy. Ann Thorac Surg 2004;78:e35.
33. Krishnamurthy M, Desai R, Patel H. Spontaneous coronary artery dissection in the postpartum period: association with antiphospholipid antibody syndrome. Heart 2004;90;e53.

34. Juszczyk M, Marnejon T, Hoffman DA. Spontaneous coronary artery dissection postpartum. J Invasive Cardiol 2004;9:524-6.

35. Jaigobin C, Silver F. Stroke secondary to postpartum coronary artery dissection. Can J Neurol Sci 2003; 30:168-70.

36. Esinler I, Yigit N, Ayhan A, et al. Coronary artery dissection during pregnancy. Acta Obstet Gynecol Scand 2003;82:194-6.

37. Dhawan R, Singh G, Fesniak H. Spontaneous coronary artery dissection: the clinical spectrum. Angiology 2002;54:89.

38. Kamineni R, Sadhu A, Alpert JS. Spontaneous coronary artery dissection: report of two cases and a 50 -year review of the literature. Cardiol Rev 2002; 10:279-84.

39. McKechnie RS, Patel D, Eitzman DT, et al. Spontaneous coronary artery dissection in a pregnant woman. Obstet Gynecol 2001;98:899-902.

40. Lerakis S, Manoukian S, Martin RP. Transesophageal echo detection of postpartum coronary artery dissection. J Am Soc Echocardiogr 2001;14:1132-3.

41. Eby CS, McBride LR. Postpartum coronary artery dissection complicated by heparin-induced thrombocytopenia and thrombosis. Ann Thorac Surg 2001;71:1025-7.

42. Lane JE, Cartledge RG, Johnson JH. Successful surgical treatment of spontaneous coronary artery dissection. Curr Surg 2001;58:316-8.

43. Togni M, Amann FW, Follath F. Spontaneous multivessel coronary artery dissection in a pregnant woman treated successfully with stent implantation. Am J Med 1999;107:407-8.

44. Vilke GM, Mahoney G, Chan TC. Postpartum coronary artery dissection. Ann Emerg Med 1998;32:260-2.

45. James AH, Jamison MG, Biswas MS , Brancazio LR, Swamy GK, Myers ER. Acute myocardial infarction in pregnancy: a United States population-based study. Circulation 2006;113:1564-71.

46. Roth A, Elkayam U. Acute myocardial infarction associated with pregnancy. J Am Coll Cardiol 2008; 52:171-80.

47. Nishikawa H, Nakanishi S, Nishiyama S, et al. Primary coronary artery dissection: its incidence, mode of onset and prognostic evaluation. J Cardiol Suppl 1988;18:307-17.

48. Zupan I, Noc M, Trinkaus D, et al. Double vessel extension of spontaneous left main coronary artery dissection in young women treated with thrombolysis. Catheter Cardiovasc Interv 2001;52:226-30.

49. Buys EM, Suttorp MJ, Morshius WJ, et al. Extension of spontaneous coronary artery dissection due to thrombolytic therapy. Cathet Cardiovasc Diagn 1994;33:157-60. 